\title{
UNIVERSITYOF
}

FORWARD

THINKING

WESTMINSTER用

WestminsterResearch

http://www.westminster.ac.uk/westminsterresearch

\section{Anonymity and Democracy: Absence as Presence in the Public Sphere}

Asenbaum, $\mathrm{H}$.

This journal article has been accepted for publication and will appear in a revised form, subsequent to peer review and/or editorial input by Cambridge University Press in the American Political Science Review.

(C) Cambridge University Press, 2018

The final definitive version in the online edition of the journal article at Cambridge Journals Online will be available at:

https://doi.org/10.1017/S0003055418000163

The WestminsterResearch online digital archive at the University of Westminster aims to make the research output of the University available to a wider audience. Copyright and Moral Rights remain with the authors and/or copyright owners.

Whilst further distribution of specific materials from within this archive is forbidden, you may freely distribute the URL of WestminsterResearch: ((http://westminsterresearch.wmin.ac.uk/)).

In case of abuse or copyright appearing without permission e-mail repository@westminster.ac.uk 


\section{ANONYMITY AND DEMOCRACY: ABSENCE AS PRESENCE IN THE PUBLIC SPHERE}

I need to become anonymous. In order to be present.

The more I am anonymous, the more I am present.

Tiqqun, 2008

\section{INTRODUCTION}

Anonymity is an essential feature of liberal democracies around the world.

The secret ballot constitutes the central legitimation mechanism. Anonymity is also crucial in a wide array of modes of political participation ranging from campaign funding to textual political debates in newspapers, manifestos, pamphlets, and graffiti. Additionally, the importance of anonymity in political participation increases as the mask becomes a focal point for social movements like Anonymous, the Black Bloc, the Zapatistas, and the Pussy Riot movement. This trend is amplified in the digital era, where anonymous expression in online newspaper forums and in activism via social media becomes an everyday practice (Asenbaum 2017). Given the crucial role of anonymity in the practices of democracy, its lack of conceptual grounding in democratic theory is surprising (cf. Gardner 2011, 939).

In contrast to the absence of anonymity in democratic theory (with Moore 2017 being a recent exception), there is a plethora of diverse, empirically driven literature discussing anonymity in various forms of political participation. This literature, however, suffers from a lack of theoretical 
attention to its main subject of research. Eric Barendt's book Anonymous Speech (2016), for example, discusses anonymity in various forms of political participation but fails to provide a definition of anonymity. The meager traces of definitions that are found in the literature on anonymity in political participation suffer first from a lack of acknowledgment of the complexity of the phenomenon. Many scholars treat anonymity as a simple and selfexplanatory concept. For example, Jonker and Pieters (2010) state: "Intuitively, anonymity means that it is impossible to determine who sent which message to whom" (216). Secondly, and more importantly, anonymity is often equated with privacy. Akdeniz' (2002) only definition of anonymity, for example, consists of the sentence: "As a concept anonymity is closely related to free speech and privacy" (224). These two interrelated shortcomings — the oversimplified definition of anonymity as privacy—result in a lack of theoretical attention to the complexity of anonymity in democracy. This essay will develop a deeper understanding and a clear definition of anonymity rooted in democratic theory. I contend that the problem with the common notion of anonymity consists in its sole focus on identity negation. This perspective results in an understanding of anonymity as privacy and thus as absence. It implicitly conceptualizes anonymity as negative freedom: the freedom from detection and interference by malevolent actors in society. Anonymity, however, consist as much of identity creation as it consists of identity negation. It entails both negative and positive freedoms. It facilitates 
expression and thus presence in the public sphere. Therefore, I define anonymity as follows:

Anonymity is a context-dependent identity performance expressing private sentiments in the public sphere by negating some aspects of the legally identified and/or physically embodied persona.

Both negating and creating identity has inherently liberating effects. Identity negation indeed affords negative freedoms, protecting the democratic subject from interference of powerful actors and peer pressure. Anonymity shares this feature with privacy. The combination of identity negation with identity creation, however, bestows the democratic subject with an array of positive freedoms to act (Berlin 1969 [1958]; cf. Fromm 1941). These freedoms are not always democratic. Berlin (1969 [1958]) explained in his elaboration on positive and negative freedoms: "[T]he liberty of some must depend on the restraint of others" (124). And the Brazilian philosopher Paulo Freire (2005 [1970]) described the fear of elites in societies marked by class, race, and gender inequality as the fear "of losing the 'freedom' to oppress" (46). Thus, the subjective freedoms of some can result in oppression of others. While on one hand anonymity contributes to a sphere of equals sincerely expressing their diverse ideas, on the other it allows for discrimination, hate speech, and lying. The contradictory character of the core elements of anonymityidentity negation and creation-results in three sets of contradictory freedoms, with each set consisting of one element conducive to and the other 
undermining democracy: (a) inclusion and exclusion, (b) subversion and submission, and (c) honesty and deception.

To develop this concept of anonymity and its affordances, I pursue two strategies. First, I review etymologies and conceptualizations of anonymity and their relation to privacy in various academic disciplines outside political science. Both their advancements and shortcomings provide inspiration for the definition of anonymity rooted in democratic theory developed here. Second, the article turns to anonymity in political participation. It briefly describes four different forms of anonymous participation: voting, campaign funding, textual political discussions, and masked collective action. It then identifies anonymity's three sets of contradictory freedoms, offering illustrations from the empirical literature on political participation. Building on these insights, I finally elaborate the theoretical conceptualization of anonymity in contrast to privacy and the workings of the three sets of contradictory freedoms in more depth, introducing three contextual axes affecting anonymity: (1) the materiality of the communicative infrastructure, (2) the positionality of the communicative subject within established power structures, and (3) the configuration of identity knowledge.

\section{WHAT IS ANONYMITY?}

The etymological development of the term "anonymity" is characterized by a continuous expansion of meaning. To trace this development, I bring together three sets of literature, moving from literature studies to computer science- 
which each describe anonymity in a specific context—and finally to more general elaborations of anonymity in communication studies, sociology, and philosophy. The same expansionary development of meaning can be observed for the term privacy. The expansions of both "anonymity" and "privacy," coalesce with the development of new communication technologies, resulting in their overlapping and partial convergence. The task undertaken here of developing a definition of anonymity rooted in democratic theory consists of disentangling anonymity and privacy.

The term "anonymous" entered the English language in the late $16^{\text {th }}$ century, and referred to publications whose authors remained unknown. While the meaning of the Greek original translating to "nameless" is already quite confined, its meaning in English was even more narrow: "Anonymity [was] defined broadly as the absence of reference to the legal name of the writer on the title page" (Griffin 1999, 882; also cf. Kopley 2016, 2). "Anonymity" thus did not refer to any kind of unidentified communication, but solely to nameless textual publications (Ferry 2002). The practice of anonymous publishing was common even before this time. It was only then, however, that the blank spaces on pamphlets, poems, and books were replaced by the word "Anonymous". The question arises as to why the blank space was not simply left blank but filled with the name-like "Anonymous". This move appears to be a collective effort to draw attention to the author and his or her conscious decision to remain unidentified. In the linguistic establishment of "anonymity" 
we thus find the first traces of identity creation rather than solely identity negation, which, as I will argue later, is the core element of anonymity.

Current conceptualizations of anonymity in computer science and technology studies illustrate the significant qualitative shift the term has undergone through the emergence of digital communication. The nameless author now becomes the unidentified communicator. The recipient of a message perceives "all subjects in the anonymity set as equally probable of being the originator of a message" (Díaz et al. 2003, 57). This literature acknowledges the complexities of anonymity as part of a communicative process exceeding textual publication. Moreover, it insists on the scalability of anonymity. Anonymity is not a state that is present or not, but a matter of degree to be measured on a scale between two opposing poles: anonymity and identity. To acknowledge the different degrees of anonymity, this literature introduces not only quantitative measures, but different types of anonymity, specifically insisting on its demarcation from "pseudonymity": the use of pseudonyms in contrast with communication without any identifier (Pfitzmann and Hansen 2010).

This qualitative shift of anonymity's meaning expressed in quite technical terms in computer science and technology studies is also recognized in communications studies, sociology, and philosophy. Exceeding definitions of anonymity in literary publications and online communication, authors such as Helen Nissenbaum and Craig Scott generate more complex understandings of 
anonymity as a social phenomenon both online and offline. Scott (1998) defines anonymity as "the degree to which a communicator perceives the message source is unknown and unspecified," (387) thus drawing attention to subjectivity: Anonymity is not an objective state but defined by the perception of communicators. Marx (1999), Wallace (1999), and Nissenbaum (1999) all draw attention to the plethora of identity markers that define a person. While for anonymous textual publishing, the name was the sole identifier, in today's information age and for an increasingly complex understanding of anonymity factors such as location (address), social security numbers, looks, social categories (race, class, gender), profession, family members, etc. are a set of highly diverse identifiers that constitute a person. Accordingly, anonymity is defined as the non-identifiability of one or several of these traits (Marx 1999) or, as Wallace (1999) describes it, "the noncoordinability of traits" (24). Nissenbaum (1999), finally, explains anonymity as unreachability: "Deepening our understanding of the issue of anonymity in an information age... requires an appreciation of what it takes to be 'unreachable' or 'out of grasp' in a world where technologies of knowledge and information are increasingly efficacious at reaching, grasping, and identifying” (143).

But if anonymity means unreachability, how, then, is it different from privacy, which can be broadly understood as an individually defined personal sphere protected from alien intrusion? In the information age, the meanings of anonymity as one's personal identity being undetectable in a communicative 
network and privacy as personal information being undetectable in a communicative network become virtually undistinguishable. The term "privacy" has undergone an expansion similar to that of anonymity (cf. Westin 1984). Its original meaning in the work of Ancient philosophers such as Aristotle and Plato referred to private property as personal control over objects (Papacharissi 2010, 27). In its modern sense, the term privacy was first used by Warren and Brandeis in 1890 as "the right to be let alone." When newspapers - at the time of the spread of the printing press in Europe and the US—started publishing details about the lives of public persons, this was perceived as an intrusion into their personal affairs. This notion of privacy thus constitutes a sphere that is shielded from external intervention. Privacy in this version has not lost its original meaning of ownership, as the private sphere is characterized by its control by the individual subject (Reiman 1976). It relies on a physical demarcation of space, distinguishing private locations (home) and public locations (cafés, squares). It is this demarcation of private and public space in the context of patriarchal modes of domination that has been aptly criticized by feminist scholars (Cohen 1992; Wagner 2015). This physical geography is upset by new forms of communication. Zizi Papacharissi (2010) goes so far as to describe the public/private dichotomy as collapsing as new online spaces are both "privately public and publicly private" (142). Public digital communication relies on private websites, with participants located in private homes being "alone, but not lonely" (132). To 
grasp this new hybridity, Nissenbaum $(1997 ; 2010)$ develops the concept of "privacy in public." The individual's control over who has access to personal information is compromised by government surveillance and commercial data mining. This new understanding of privacy still contains original elements of personal control and the demarcation of a sphere to be left alone. It is uprooted, however, by the physical dislocation of this sphere. Privacy becomes mobile.

This brief review explains why and how the terms anonymity and privacy overlap. Their parallel expansion in meaning has peaked following their digitization, resulting in overlapping and blurring understandings. Looking at the conceptualizations of anonymity above, a new understanding of anonymity must not only overcome this amalgamation, it has several other challenges to face. Current discussions successfully deepen the understanding of anonymity by explaining it as subjective, a matter of degree, depending on various identifiers, and resulting in several types of anonymity.

However, these definitions suffer first from heir conceptualization of anonymity as mere identity negation, neglecting the possibilities of identity creation. This is observable in relation to terms such as unidentifiability, unknowability, undetectability, unreachability, and noncoordinability. These terms explain anonymity as the impossibility of the identification of communicators by the audience, rather than as action by communicators themselves. The sole focus on identity negation is also evident when 
anonymity is defined as the opposite of identity. Second, this is also another reason why anonymity and privacy appear so closely related. When anonymity is conceptualized as concealing identity and privacy as restricting access to personal information, they are hardly distinguishable. Third, the terms employed to describe anonymity do not coincidently share the suffix -ity, which indicates that they are conceptualized as state rather than as process. And fourth, the differentiation of types of anonymity is helpful to a certain extent. But terms like pseudonymity, physical anonymity, discursive anonymity, offline anonymity, online anonymity, self-anonymity, otheranonymity (Scott 1999), agent anonymity, recipient anonymity, and process anonymity (Wallace 1999) can lead to confusion and over-complexity. A new definition of anonymity must provide clarity and, at the same time, encompass these various subtypes of anonymity.

I generate this new definition of anonymity by drawing on two concepts rooted in democratic theory: the public sphere and positive liberties. First, current understandings of anonymity as closely related to privacy emerge from the position of concern over the infringement of civil rights. The alignment with privacy results in defensiveness. In contrast, I suggest drawing on democratic theory's rich accounts of the public sphere (Fraser 1990, Habermas 1992 [1962]). Anonymity is inherently communicative. It is not primarily a matter of hiding, but of showing, exchanging opinions, and creating identities. Second, the inherently liberating effects of anonymity as unidentifiability have 
been conceptualized as negative freedoms, freedoms to be protected from external intrusion. Again, the overlap with privacy becomes apparent.

However, I suggest that we also need to take positive freedoms, as freedoms to act, into account. Thus, while privacy is closely related to negative freedoms protecting from intrusion, anonymity relates to positive freedoms of expression and identity creation.

Since the original conceptualization of negative and positive freedoms by Erich Fromm (1941) and later Isaiah Berlin (1969 [1958]), critics have contended that the two cannot be easily demarcated, since every freedom contains both positive and negative aspects (Blau 2004; MacCallum 1967). I agree with and build on this critique by drawing attention to the positive freedoms of anonymity that add to its negative freedoms of concealment and protection. Thus, while anonymity in current debates is conceptualized as the impossibility of interlocutors to identify the subject, I define anonymity as the self-expression of the democratic subject. Anonymity is not the opposite of identity, it is a pre-condition for creating identity drawing on both positive and negative freedoms. I therefore define anonymity as follows:

Anonymity is a context-dependent identity performance expressing private sentiments in the public sphere by negating some aspects of the legally identified and/or physically embodied persona.

In contrast with previous definitions, it gives priority to the creative and constructive aspects of anonymity, while not neglecting its concealing and 
negating aspects. Moreover, it defines it as a public, communicative process, rather than a private state, stressing its discursive and agentic nature. And finally, it is broad enough to encompass various subtypes, both providing unity and allowing for differentiations. The following sections will investigate the workings of anonymity in various forms of political participation and illustrate how its positive freedoms facilitate both democratic and antidemocratic action.

\section{ANONYMITY IN DIFFERENT MODES OF POLITICAL PARTICIPATION}

Anonymity plays a key role in different modes of political participation. In what follows, I briefly outline anonymous (a) voting, (b) campaign funding, (c) textual political discussions, and (d) masked collective action.

Voting as the central mode of political participation in representative democracies is in its current practice strongly linked to the notion of anonymity. However, the correlation of anonymity and voting is relatively recent. Open voting either by voice, raising of hands or on a visually identifiable ballot provided by different parties in different colors was the common practice in the US for more than 100 years from its founding in 1789 . Under these circumstances, political parties heavily influenced citizens' voting behavior either by threat or patronage. This was the reasoning behind introducing the secret ballot in the US and UK in the late $19^{\text {th }}$ century (Barendt 2016, 156ff; Gardner 2011, 942; Hunter 2002). The opposite legal trend to 
voting procedures, from anonymity to public identification, took place in the case of private campaign contributions. In the late $20^{\text {th }}$ century, the mandatory disclosure of financial contributions exceeding a certain amount to candidates and political parties was introduced in the US (Gardner 2011, 944).

Nevertheless, anonymity is still in place in most countries for donations below a certain amount.

Anonymity in textual political discussions has been addressed empirically in at least three forms: the publication of political texts, graffiti, and online communication. First, Smith Ekstrand and Imfeld Jeyaram (2011) extensively elaborate on the role of anonymity in the political controversy between Federalists and Anti-Federalists in the debate of the US Constitution in 1787. The use of pseudonyms was essential in this debate and built on a long European tradition of anonymous publication. Second, anonymity is a core feature of graffiti in public bathrooms as examined at one US and one Australian university campus (Butler 2006; Rodriguez and Clair 1999). Far from just scribbling slogans or jokes, graffiti appear as extensive dialogues between students who negotiate their gender, sexuality, race, and political views. Third, the medium of bathroom walls is surprisingly comparable to online forums. Participants post messages and check back some time later to see if someone responded. With the advent of the Internet, textual anonymous discussions have become more prevalent, with increasing publication speed and reach and reduced costs (Akdeniz 2002; Gardner 2011, 945; Leitner 2015; 
Woo 2006). While asynchronous posts in online forums are reminiscent of anonymous political writings from the $18^{\text {th }}$ century and bathroom wall graffiti, real-time chats make political writing more akin to live discussions.

Another strand of literature investigates masked collective action used by both pro- and anti-democratic social movements and civil society organizations. Pro-democratic movements use masking to turn demonstrations into street parties with clownesque performances, street theatre, and carnivalesque tactics of disguise (Bruner 2005; Morris 2012; Ruiz 2013; Spiegel 2015). An example of such a carnivalesque guerilla performance can be found in the Russian feminist collective Pussy Riot who performed their "Punk Prayer" at Moscow's Cathedral of Christ the Savior in 2012. Three of the five women masked by colorful balaclavas were arrested and jailed. A global movement in solidarity with Pussy Riot re-enacted the mockery of authority with the colorful balaclavas as their symbol. This form of political participation builds on carnival traditions dating back to ancient Rome. Medieval carnival was more political than its commercialized rendition today. The tradition of people taking to the streets in disguise was used to challenge authorities through mockery and enact a reversal of social hierarchies (Bruner 2005). Similar practices of masking are used in online protest by hacktivist groups like Anonymous. It uses anonymous online communication to attack Scientology, global corporations, and national governments around the world and promotes freedom of speech and social justice (Asenbaum 2017; Coleman 2014). The 
Black Lives Matter movement uses the guise of hoods to enact solidarity with victims of hate crimes and police brutality who are criminalized because of wearing hoodies. The "Million Hoodie March" can be read as a proud reclaiming of a marginalized race/class identity (Kinney 2016; Nguyen 2015). On the other hand, the Ku Klux Klan, as an example of an anti-democratic movement, uses anonymity to enact white racial homogeneity through uniform white hoods and racist acts of intimidation and murder. Emerging in 1865 in the US South, it fast became the largest and most influential white supremacist movement (Blee and McDowell 1999). This example also illustrates that anonymous hate crimes predate the Internet. The connectivity and reach of the KKK is, however, amplified today by the use of online communication (Schmitz 2016).

While anonymous voting, campaign funding, textual political discussions, and masked collective action appear as quite distinct forms of political participation, the discussion of the freedoms afforded by anonymity in the following section reveals surprising similarities.

\section{ANONYMITY'S CONTRADICTORY FREEDOMS}

The starting point for developing a more complex understanding of anonymity beyond a mere equation with privacy, is the observation that anonymity does not only facilitate identity negation but also affords identity creation. Sociologists like Erving Goffman (1956) pointed out decades ago that new 
identities are constructed on the foundation of the hidden identity. The maskbe it physical or virtual—serves both identity negation and creation.

In the literature on anonymous political participation, identity negation is framed in terms of freedom of speech. Concealing identity appears necessary in the face of various repressive forces in society. Anonymity appears as negative freedom — as a means of becoming invisible and avoiding detection. Regarding online communication, Akdeniz (2002) argues: “Apart from facilitating freedom of expression, anonymity enables users to prevent surveillance and monitoring of their activities on the Internet from commercial companies and from the government" (233). Identity negation does, however, not only protect from interference of state and economic actors but also from peer pressure by family, friends, and colleagues. According to Barendt, the secret ballot was introduced in the late $19^{\text {th }}$ century in the US and UK not only to protect workers from their employers; the voting booth also proved especially important to women gaining suffrage in the early- and mid-20 ${ }^{\text {th }}$ century as it shielded from the influence of husbands and fathers (Barendt 2016, 156ff).

Identity negation, be it through voting booths, computer screens, or masks, results in the emergence of new imaginaries and alternative personae. Ruiz (2013) claims: "[T]he mask does not negate identity; instead it signifies the possibility of a multiplicity of identities... It suggests a way of thinking about blankness as a means not only of erasing difference but also as a means of 
articulating difference" (275). Employing anonymity bestows democratic subjects with the ability to reinvent their appearance and thus influence their perception by others, be it through wearing a mask, designing an avatar, or creating a pseudonym. The literature on masked collective action interprets playful experimentation with a diversity of identities as having liberating effects. The democratic subject is temporarily relieved from the constraints of the one and only identity in the public sphere, which is subject to governance surveillance and commercial targeting. Mikhail Bakhtin (1996 [1968]), a prominent scholar on the carnivalesque, wrote: "The mask is connected with the joy of change and reincarnation, with gay relativity and merry negation of uniformity and similarity; it rejects conformity to oneself' (39, emphasis added).

Based on this core contradiction of identity negation and creation as anonymity's founding elements, three sets of contradictory freedoms emerge, each consisting of one democratic and one anti-democratic element. Anonymity in democracy serves (a) inclusion and exclusion, (b) subversion and submission, and (c) honesty and deception.

\section{Inclusion and Exclusion}

Nowhere does the contradictory character of anonymity become so apparent as in the discussion of inclusion and exclusion. On the one hand, anonymity appears to level the playing field by stripping away hierarchizing identity markers, generating a more inclusive participatory space. On the other hand, 
anonymity's disinhibition effect (Suler 2004) contributes to attacks on marginalized social groups in an attempt to exclude those deemed inferior.

Inclusion. The common argument for the equalizing effect of anonymity claims that social hierarchies are suspended—or at least their effects are mitigatedby concealing visible markers of gender, race, socio-economic status, age, and so on, thus contributing to inclusion. In the words of Leitner (2015), for example: "[C]yberspace represents a sphere of existence free from (or at least freer from) socio-economic inequalities and social constraints. Without the exante requirement of self-identification, individuals can equally share in the personal freedom to choose how to express themselves, including whether and how to self-identify" (167).

While unequal power relations are not simply suspended on the Internet, anonymity appears at times to contribute to more equal relations. Similarly, among participants of bathroom graffiti, anonymity structurally impedes discrimination along visual identity markers. While identity clues might persist in writing, physically embodied signifiers of social status are suspended: "[G]raffiti level the playing field by getting past all of the factors-such as social status, hierarchical position, education, access, familiarity with rules, expertise, communication competence-that advantageously privilege and benefit certain members against others" (Rodriguez and Clair 1999, 2). The same argument is made by activists in the Pussy Riot movement. After their arrests the media revealed personal details about band members and stylized 
them as celebrities. In contrast, anonymous Pussy Riot members claim: "We are anonymous because we act against any personality cult, against hierarchies implied by appearance, age and other visible social attributes. We cover our heads because we oppose the very idea of using female faces as trademark for promoting any sort of goods or services" (cited in Groeneveld 2015, 10).

These equalizing effects of anonymity result in meritocracy. While in nonanonymous settings identity markers indicating the status of the speaker influence the perception of what is said, anonymous communication can only be judged by the value of its content. A participant of bathroom graffiti explains: "I like toilet walls because there's no identity. Because if you knew who wrote it, you could think 'oh, I don't like that person, I'm not going to respond well to what they said', but if you don't know who wrote it, you're going to respond with whatever you think is the best response" (cited in Butler 2006, 23). This argument is curiously echoed in the US constitutional debate: Melancton Smith, writing under the pseudonym Plebeian, claimed that arguments should be judged "on their own merits. If it be good, it stands not in need of great men's names to support it. If it be bad, their names ought not to sanction it" (cited in Smith Ekstrand and Imfeld Jeyaram 2011, 46).

The principle of meritocracy is also at the center of both the ideology and practices of Anonymous. The hacktivist collective originated on the image board 4chan and its sub-board /b/, where mostly young North Americans share and discuss digital images with complete anonymity. "With no method of 
individual identity verification, /b/ becomes a community made up of nonpersistent individual identities. When you post on /b/, nobody can prejudge you based on your looks, age, wealth, status, or style. They only have your words" (Wesch et al. 2012, 92f). The ephemerality of the site, with every post expiring as new posts appear, can be interpreted in terms of a critique of digital archiving and monitoring. McDonald $(2015,979)$ sees 4 chan and Anonymous as antitheses to the Facebook culture of naming, liking, and tagging, which connects value to the persona and not the content, and creates an archive easily abused for surveillance (cf. Cambre 2014, 305). This leads Halpin (2012) to interpret Anonymous as an anti-capitalist project:

"Anonymous [...] is an ontological shift on the terrain of identity at the very moment that identity has become the highest form of selection and exploitation in cognitive capitalism, the first glimpse of life without identity on the Internet" (19).

The notion of anonymity as destabilizing capitalist hierarchies by countering personality cult also resonates in the literature on masked protest (Morris 2012, 110; Ruiz 2013, 270). Social movements are framed in opposition to capitalist inequality as a place of horizontality, reciprocity, and solidarity. The movement itself appears as democratic utopia. This inclusive agenda is expressed in frames like the slogans of the Occupy movement "We are the 99\%", Anonymous "We are Anonymous We are legion”, the Mexican Zapatistas "We are you", the Pussy Riot movement "We are all Pussy Riot", 
and the Black Lives Matter movement "We are all Trayvon Martin". All these slogans start with self-definitions rather than political claims. The identification "We are" is then followed by a broad, inclusive term. The "We" is constructed as inclusive space for (almost) everyone. Thus, not only the negation of hierarchizing identity markers but also the creation of new collective identities can lead to inclusion. Ruiz (2013) elaborates: “[T]he mask creates a space that can be occupied by those who perceive themselves to be excluded and that explicitly refuses to shape or filter that which could be heard" (274).

Exclusion. The freedom to oppress and exclude is facilitated by anonymity when identity negation is used to avoid accountability and discriminate against those whose positions are marginalized within society. These acts aim to keep members of marginalized groups out of social and political spaces, especially those with decision making capacities.

The Ku Klux Klan represents a telling example of the exclusive potential of anonymity. Here, anonymity is used in an attempt to cast out members of certain social groups in order to form a homogenous cultural and racial unity. The most appalling use of anonymity can be observed in racist hate crimes and the murder of African Americans in the 1920s (Blee and McDowell 1999). In these cases, masking was used in public lynchings to avoid detection. While today the KKK does not engage in public executions, their ideology of white supremacy that is disseminated via social media shows how the Klan upholds 
its original ideas of racial purity (Schmitz 2016). The goal of such actions is to expel particular ethnic groups that are perceived as a threat to their own culturally cognate community.

The example of the KKK illustrates how not only identity negation, but also identity creation, can be used for exclusion. While members of the first KKK in the second half of the $19^{\text {th }}$ century wore various eclectic self-made robes, masks, and hoods, the second KKK founded in 1915-heavily inspired by the movie Birth of a Nation - adopted the uniform white robes with conical hats still worn by its third generation today. These ghost-like figures are meant to intimidate their victims. Moreover, Schmitz' study of the KKK's ideology, as expressed on its various webpages, shows that racism toward non-members is not the only line of discrimination. Rather, websites also contain misogynist and heteronormative content. Most pages exclusively display Klansmen, often in military attire and combat, while women are underrepresented and depicted as housewives (Schmitz 2016, 208ff). The anonymity of the hood eradicating gender differences in a universalizing move enacts KKK members as default men, which deters women from participating in the Klan.

Anonymity's affordance of exclusion does not always take the form of blatant discrimination. It can take more subtle forms, when social and economic elites use their financial power to gain exclusive access to decision-making spaces. When economic actors influence the legislative process directly through lobbying and corruption and indirectly through campaign and party funding, 
they effectively buy access to an exclusive space. The doors to the public are shut. Where there are no transparency laws in place requiring the identification of donors, anonymous financial contributions establish secret connections between the donor and the candidate or party. The donor is known to the beneficiary; however, he or she is unknown to the public. While in clear cases of corruption the donation is tied to explicit political demands, in less explicit cases the beneficiary might act in the interest of the donor in expectation of future advantages. Such concerns were raised in 1997 when the British Labor Government proposed to exempt motor racing from a ban on tobacco advertising shortly after the Labor Party received a $£ 1$ million donation from business magnate and Formula One chief executive, Bernie Ecclestone (Barendt 2016, 163ff). Thus, anonymous party financing can distort legislative processes, which translates economic inequality into political exclusion.

Another example of more subtle forms of exclusion afforded by anonymity can be found in the practice of voice vote in the US Congress. While the roll call voting record, which identifies the voting behavior of each Congress member individually, has established itself as the dominant practice in modern congressional procedures, the default version still practiced today is the voice vote. Here yeas and nays are each expressed verbally and collectively so that the individual vote of the respective Congress member remains unknown to the public. The chair then gauges the majority and decides the vote. This 
procedure, which is the original practice of the US Congress, undermines transparency and parliamentary accountability. Obscuring voting behavior effectively shuts the public out and metaphorically speaking closes the doors of parliament to public scrutiny. Lynch and Madonna (2103) find that elections incentivize Congress members to request a recorded roll call vote. Thus, while the competition for seats enhances transparency, voice voting is still a common practice when members of Congress want to conceal their voting behavior on controversial issues.

\section{Subversion and Submission}

By allowing dissidents and marginalized groups to avoid detection (identity negation) and to form new collective identities (identity creation), anonymity facilitates the contestation of hegemonic power structures. Simultaneously, however, anonymity can be used to submit subversive subjects and those at the bottom of power structures when it is used to discipline and maintain established inequalities. Anonymity thus facilitates both subversion and submission.

Subversion. Some of the most influential texts contesting political power relations that are today clearly attributed to certain authors were originally published anonymously, such as Thomas Paine's Common Sense attacking the English government published in 1776 by “an Englishman.” The Communist Manifesto by Karl Marx and Friedrich Engels calling for a proletarian revolution was published anonymously in 1848 and only attributed to its 
authors in 1872 .

The importance of anonymity for subversion has not decreased since. Morris (2012) argues that neoliberal developments of commodification and surveillance create a political context in which anonymity becomes an empowering tool: “Anonymity is not only a politically-motivated response to the encroachments of data-gathering devices and the bioinformatics that underwrite the impersonal efficiency of contemporary biopolitical control societies. It is also an aesthetic revolt against the era of navel-gazing narcissism that has hypnotized the subject of these regimes... A form of resistance to the State, then, is to eliminate its access to its economic subjects by scrambling the informatics networks it uses to delineate, organize and manage them, effectively de-activating oneself as a political subject" (110). Whistleblowing, for example, is a subversive practices, where individuals "leak" information on illegal or immoral actions from an insider perspective (Barendt 2016, 75). This contests capitalist logics of privatization and commodification of knowledge. WikiLeaks—as prominent exampleprovides a website for the anonymous publication of information on US governmental wrongdoings. In 2010, Bradley/Chelsea Manning, a soldier in gender transition, leaked the greatest amount of classified military and diplomatic documents to the public in US history via WikiLeaks and other channels exposing human rights violations like the purposeful killing of civilians by the US-military in Iraq and Afghanistan. The story of WikiLeaks 
appears at the center of a global cultural rupture of identity reconfigurations. The anonymity of its whistleblowing practices contrasts dramatically with the celebrity status of Julian Assange, its public face overshadowing the drama of Manning, a young person searching for a new identity between army barracks and prison walls.

WikiLeaks is part of a broader "freedom of information movement" (Beyer 2014; McCarthy 2015), evolving from the hacker counter culture that upholds the principle of free speech and open source. Political groups like the Pirate Party derive their name from the notion of online piracy, consisting of stealing and publically sharing digital private property. Anonymous is another actor in the freedom of information movement that engages in the practices of hacking and leaking. It is most notoriously known for its Distributed Denial of Service Attacks (DDoS), making their opponents' websites inaccessible. This tactic is often equated with analogous forms of civil disobedience like sit-ins or occupations. Anonymous illustrates how employing anonymity enables some "computer nerds" to inflict serious harm on powerful institutions like the Church of Scientology, Visa and MasterCard, and governments around the world (Asenbaum 2017).

The mask becomes a common focal point of diverse movements contesting practices of identification and surveillance. What the Guy Fawkes mask is for Anonymous, the colorful balaclava is for the Pussy Riot movement. In contrast to the white faced, bearded man who is associated with the digital 
culture of disembodiment and Western reason, the hand-knit balaclavas in different colors enact physical embodiment, femininity, cultural diversity, and passion. This contrast between Pussy Riot and Anonymous shows how Pussy Riot's performative interventions are deeply rooted in a feminist contestation of patriarchy. Pussy Riot's “Punk Prayer” directly attacked Vladimir Putin’s government and the Russian Orthodox church, the two centers of patriarchal rule in Russia. The global movement in support of Pussy Riot reinterprets these objectives from a Western perspective as protest against state surveillance and police brutality. Interpreting an image of a policeman pulling the balaclava off a female protester's face at a US solidarity demonstration with Pussy Riot, Bruce (2015) states: "In this image the balaclava circulates as vehicle for drawing parallels between US and Russian state repression” (54).

Not coincidentally did Pussy Riot stage their "Punk Prayer" protest in February - the carnival season. Medieval carnival provided a temporal chance to enact the inversion of social hierarchies as "the lower classes had an opportunity to dress up as the ruling classes and mock their power" (Spiegel 2015, 808). Political dissidents and disenfranchised groups “used carnival festivities to critique government officials and state institutions and demand significant political reform" (Bruner 2012, 139). Bruner reports one such example: In 1580 Romans-sur-Isére, a small town in France, the gap between the rich and the poor widened as the ruling elite exempted themselves from paying taxes. In response, the carnival festivities organized by the common 
people ran under the theme "eat the rich". The crowd in disguise held mock armed military parades, marched with rakes and brooms to sweep away the rich, and enacted selling the meat of the rich at a market. This fictive performance had real consequences as the mock rebel leaders were prosecuted, tortured, and hanged (Bruner 2005, 142).

The parallels to Pussy Riot's "Punk Prayer" are apparent: "Medieval carnival is known to have included mockery of church authorities, even swearing and indecent behavior from pulpits and altars" (Steinholt 2013, 123). While both Pussy Riot and medieval carnival encompass elements of humor, they combine these with serious threat. The threat "eat the rich" is echoed by the chorus of the Punk Prayer "Virgin Mary, chase Putin away." The Punk Prayer consists of aggressive rock music and swear words. The balaclava itself, however colorful, contains aspects of threat: "[T]he circulatory power of the balaclava means that such endless reproduction can become monstrous and terrifying" (Bruce 2015, 49). This can also be observed in the techniques of the black bloc in anti-capitalist demonstrations. Hiding their faces behind black balaclavas, scarves, and hoods, the creation of a menacing persona is not an unintentional side effect as an anti-globalization protester explains: "part of the effectiveness of our mass mobilizations rest on this threat of implied violence" (cited in Ruiz 2013, 269).

Hiding faces in hoods is also an essential practice in the Black Lives Matter movement. The hood affords a performance of defiance through its association 
with youth riots, gang wars, and anti-capitalist insurgency. In the "Million Hoodie March" hundreds took to the streets of New York City in hoods to protest the killing of Trayvon Martin, a 17-year-old African American, whose killer, white neighborhood watchman George Zimmerman, went free. As the anonymity of Martin's hood was blamed for creating a threat which justified Zimmerman's actions, Black Lives Matter activists wear hoodies to perform solidarity with the victim and claim their race/class identity (Kinney 2016; Nguyen 2015). Kinney (2016) elaborates: "But even when, and sometimes because, authorities brand the hood as criminal or illegitimate, people keep wearing their hoods for resistance, revolution, and transformation. For selfexpression, defiance, and play" (71).

Submission. While anonymity promotes subversive tendencies in society when it is used by subaltern subjects, it can have the reverse effect when it is employed by those in positions of power. Anonymity can unfurl disciplinary power and work to maintain established hierarchies. In contrast with the freedom to exclude, rather than expelling the subaltern, the freedom to submit disciplines the subject to alter its behavior and restrict it to its subjugate position while keeping it within the community.

In many countries, riot police concerned with maintaining public order at demonstrations and protests increasingly appear masked. While these black masks (either in the form of balaclavas or gas masks) serve physical protection, they also fulfill the double function of anonymity: negating and 
creating identity. First, by concealing identity, police evade personal identification and escape public scrutiny. This goes along with trends of police refusing to wear their badge numbers and restricting civilians from filming their actions, which is most frequently observed in the context of police brutality against ethnic minorities (Spiegel 2015, 791f). Second, anonymity also allows police to construct menacing personae. Riot police uniforms are more akin to soldiers' military gear evoking an image of an army at war. While the camouflage of military uniforms is meant to let soldiers disappear, black uniforms signal presence, threat, and unity. Thus, anonymity is employed to enhance police's ability to remain order and discipline subversive subjects.

The power imbalance between anonymous police and demonstrators is amplified by bans on mask wearing in public gatherings. The Canadian federal ban on masks implemented in 2012, for example, punishes mask wearing with up to 10 years of imprisonment. This inverts the logic of liberal democracies making state actors identifiable to be held accountable by the public and simultaneously upholding citizens' right to privacy. According to Spiegel (2015), these tendencies need to be interpreted in a wider context: "In the United States, cases of individuals arrested and charged for filming police officers multiply, while high-profile cases such as those of Chelsea Manning and Edward Snowden, both charged with breaching national security for exposing to the American people state documents concerning American 
government activity, further anchor the asymmetrical logic of coding and surveilling individuals while obscuring the actions of public forces that, in principle, serve and answer to these same individuals" (791f).

These tendencies cannot only be observed in physical gatherings but also in online communication. The Internet amplifies possibilities of surveillance: “[U]sers' identities have become increasingly exposed, while the subject of surveillance and their activities have become less identifiable. Therefore, the major impetus for the power imbalance between the subject and the object of surveillance in the network is their differences in identifiability" (Woo 2005, 961).

The disciplinary function of anonymity is not only used against protestors and insurgent minorities, but against marginalized groups more generally as privileged groups assert their dominance. This is the central observation in Rodriguez and Clair's (1999) analysis of bathroom graffiti. While they acknowledge graffiti as important outlet for suppressed anger, they also observe that it is used by those on the top of hierarchies to affirm their position: "[D]ominant groups—especially white heterosexual men-use the open nature of graffiti to intimidate and 'discipline' minority groups... graffiti allow for open discourse (sexist, racist, and homophobic speech) that organizations cannot sanction, but which may also act to establish or reinforce the privileging aspects of patriarchal practice, thus, supporting the hegemonic order" (3). While anonymity's freedom to exclude is used in the politics of 
extreme right-wing groups to keep those perceived as inferior out of communal space, submission, to the contrary, keeps them in place-in their subjugate position. Thus, women are excluded from decision-making spaces as in the example of the KKK cited above, but submitted in social spaces like a university campus through sexist discourses in bathroom graffiti.

A last example illustrates that submission through anonymity is not only at work in unequal power struggles but can also affect struggles between peers. The phenomenon of hate speech and "flaming", which is discussed today mostly in the context of online anonymity, is expressed not only in graffiti but also was well known to participants in the US constitutional debate. Addressing insults to each other's pseudonyms Federalists and Anti-Federalists used terms like "ignorant loggerhead" and "ungrateful monster" to submit their respective opponent (Smith Ekstrand and Imfeld Jeyaram 2011 43). "An onslaught of sparring and often libellous remarks appeared in newspapers and pamphlets... The absence of an author's true identity, however, did not spare anonymous authors from attack and may have indeed made such attacks easier" (ibid. 39, 43).

\section{Honesty and Deception}

Lastly, accounts of anonymity in political participation describe how anonymous participants are more willing to reveal their true beliefs. Identity negation avoids peer pressure which in turn leads to more sincerity in public discourse. Others, however, point to anonymity's affordance of lying as it 
allows for the construction of fake identities and encourages deceit through a lack of accountability. Anonymity thus appears to contribute to both more honesty and more deception in democracy.

Honesty. Oscar Wilde famously wrote: "Man is least himself when he talks in his own person. Give him a mask and he will tell you the truth" (Wilde 2007 [1861]). These words were based on $19^{\text {th }}$ century practices of masked balls and anonymously published novels that often contained strong political undertones (Barendt 2016, 14). The same can be observed today in all modes of anonymous political participation discussed here: escaping domination through anonymity—-be it from state institutions, private actors, or peerscontributes to a diversity of opinions in the public sphere: "There are certain unpopular positions which some people might want to explore, but not if they know they will be exposed to ridicule and perhaps even physical harm if they are tied to such views in public. To completely forbid anonymity would therefore result in no unorthodox views ever reaching the public sphere of debate" (Hunter 2002).

In elections, voters can uninhibitedly express their interests anonymously. Similarly, anonymity is used in polling to detect the electorate's true preferences on various political issues (Kuran 1993, 41f). Anonymity's freedom to speak the truth also plays into the freedom to subvert as anonymous movements challenge authority. Dissidents like Pussy Riot and Anonymous reveal their true beliefs when shielded by anonymity. Anonymous 
media are established as truth-promoting institutions such as WikiLeaks' whistleblowing website or Anonymous' independent media channel anonews.co that challenges the mainstream media narratives of current events (cf. McDonald 2015). However, honesty does not only contribute to subversion but also to exclusion and submission. Aggressive and derogatory speech directed at marginalized groups is an expression of true sentiment. Thus, Gardner's two sides of anonymity might actually be seen as one and the same phenomenon: "[A]nonymity has been both praised for freeing citizens to vote and speak their true beliefs, and condemned for providing convenient cover to harmful or democratically undesirable behavior" (Gardner 2011, 929).

Both Butler (2006) and Rodriguez and Clair (1999) report in their respective accounts on bathroom graffiti on university campuses how these anonymous dialogues between students are used to verbalize political opinions that are deemed inappropriate in classrooms and student newspapers. Thus, the more formally regulated public sphere has exclusive effects: "Graffiti allow the key benefit of anonymity, that is, protection against any form of retribution. All can say whatever, however, and whenever, to whomever" (Rodriguez and Clair 1999, 2). Rodriguez and Clair claim that the bathroom stall functions as a kind of confession booth where both social identities and political views are expressed and negotiated. One might add the comparison to a voting booth, also serving the expression of true beliefs. The study of bathroom graffiti at a 
US university with predominantly African American students in the late 1990s shows how under conditions of anonymity taboo topics like homosexuality could be addressed. As the following dialogue shows, both sides of the argument—those defending and those opposing homosexuality—expressed their opinions in a candid and unrestricted manner:

“(D) I really don't understand how a woman could be attracted to another woman and I agree with the sister girl to the left of me. Homosexuality is very unnatural and since God says its wrong in the bible I don't [think] he would create a human being that way. It's a learned behavior.

(E) You have to learn to interpret the bible. King James was a racist woman hater. Reading is Fundamental. You also think God is a HE. Question everything that contradicts your Freedom and liberty.

(A) African American women. Look! Don't judge people. You don't understand homosexuality at all! If it was a choice I wouldn't choose it because of all the abuse. Why can't I just be myself in this world?" (cited in Rodriguez and Clair 1999, 6ff)

This dialogue is indicative for a few reasons. Not only can the construction of sexual identity be observed, but we can also witness a genuine dialogue that most likely never would have taken place without an anonymous medium. The question (A) poses at the end is especially telling: "Why can't I just be myself in this world?" implies that she can express her real self publicly only under conditions of anonymity. Both freedoms of subversion of hegemonic identity 
constructions and submission within a peer group resulting from frankly speaking one's mind can be observed in the dialogue.

The case of bathroom graffiti illustrates that anonymity is especially important to marginalized social groups to publicly express their identities. The Internet provides another outlet to articulate queer identities. Leitner elaborates the situation of LGBTIQs in South Korea who often face stigmatism and social ostracism: "[M]any persons identifying with a homosexual (or other nonheterosexual) identity find an anonymous Internet to be the only recourse for open expression... A lack of expressive opportunity deprives homosexual persons of reasonable opportunities to develop their identities" (Leitner 2015, 210). In countries with more accepting cultures toward queer sexualities, anonymity nevertheless plays an important role. Annual Gay Pride parades are characterized by masquerade and carnivalesque identity performances enacting gender changes and fusions (Baxter 2015).

Deception. Paradoxically, while enabling a more honest discourse by concealing identity is an undisputed feature of anonymity, facilitating deceit appears just as plausible. In his notebooks from the late $15^{\text {th }}$ and early $16^{\text {th }}$ century, Leonardo da Vinci wrote: "Fire is to represent truth because it destroys all sophistry and lies; and the mask is for lying and falsehood which conceal truth" (da Vinci 2005, 684).

While today hiding one's identity when casting the ballot in elections is perceived as a core political right, the role of the secret ballot was far more 
contested in $19^{\text {th }}$ century Britain: "[S]ecret voting was contrary to the English cultural traditions of honesty and openness; it would lead to habits of falsehood and deception" (Barendt 2016, 157). While one was supposed to vote in accordance with the common good, the secret ballot gave the opportunity for selfish voting, either concealing or even lying about one's decision. Voting based on the common good was particularly important in the face of exclusion of certain social groups-most prominently women-from the suffrage. Thus, John Stuart Mill argued men had to reveal their voting behavior not only to a wider public, but specifically to their wives and daughters whose interests they were supposed to include (ibid.).

In contrast to single voting acts, the Internet provides multiple and continuous opportunities for deception. The case of A Gay Girl in Damascus is a telling example. In the wake of the uprisings in Arab countries in 2011, the blog $A$ Gay Girl in Damascus told the personal story of the Syrian LGBTIQ activist Amina, resisting the ultra-conservative Syrian regime from within. Amina's blog posts were promoted by Lez Get Real, an US-based LGBTIQ news website run by Paula Brooks. After the blog rapidly rose in popularity in just a few months, news spread that Amina was abducted, causing her loyal community to spring into action under the hashtag \#FreeAmina. Soon it turned out Amina was really Tom MacMaster, a forty-year old, white, heterosexual American man. Paula Brooks, who had promoted Amina's blog through Lez Get Real and engaged in private and allegedly romantic contact with Amina, 
later turned out to be Bill Graber, a fifty-seven-year-old, heterosexual American. Both men claimed to have invented fictive personae to more credibly rally for a social group they were not part of. Cardell and Maguire's (2015) pointed analysis uncovers the relevance of the power structures the case is contextualized within: "The hoax is dangerous because it cloaks the dominant narrative under the disguise of a subversive narrator who corroborates rather than disrupts the dominant narrative...It places a US readership in the privileged position of cardcarrying listener to the voice of a subordinate object whose 'true' story confirms the rightness of Western democracy and Orientalist discourses about Middle Eastern Otherness, evident, for example, in the cultural stereotype of the Arab woman as being in need of rescuing" (215f).

Conscious deceit is also used to troll or infiltrate political opponents and to spread fake news. Anonymous, for example, employed deception facilitated by anonymity to attack the white supremacist Hal Turner. Turner propagated racist views via his radio show and web site. Anonymous activists flooded the radio show with anonymous prank phone calls and the website with prank comments (Coleman 2014, 19f). This incidence is not an isolated case. Groups like Expose attempt to document illegal content of extreme right groups online and report it to the police. While this is not the official policy of the group, some members create fake accounts on social media—so-called "sock puppets"- to post racist comments, add right-wing individuals as friends, and 
like right-wing groups to gain the trust of the online community. When they are ultimately invited to secret chat rooms where strategy and future actions are planned, they gain access to valuable information (Bartlett 2015, 62ff). More sophisticated forms of deception are employed when anonymous programmers design social bots to present themselves as people on social media. On Twitter, bots simulating political supporters or activist groups tweet and retweet political content, heavily influencing which political messages are read online and potentially swaying election and referendum results. Both the campaigns of Donald Trump for US President in 2016 and for Brexit in the UK referendum in the same year were heavily supported by artificial agents whose puppeteers remained in the dark (Bastos and Mercea 2017; Bessi and Ferrara 2016).

\section{ABSENCE AS PRESENCE IN THE PUBLIC SPHERE}

When considering the antithetical character of anonymity as identity negation and creation and the resulting three sets of contradictory freedoms, the stark contrast between privacy and anonymity becomes evident: Neither inclusion, exclusion, subversion, submission, honesty, nor deception have much, if anything, in common with privacy. This is because they all relate to a crucial aspect of anonymity besides concealment. They all hint at the inherently discursive character of anonymity. This is also illustrated by the four modes of anonymous political participation discussed above: Voting, campaign funding, political writing, and masked collective action are all modes of 
communication in the public sphere. Thus, anonymity does not entail being let alone. On the contrary, anonymity only exists within a public discursive arena. The public sphere - the opposite of privacy - is the precondition for anonymity (cf. Barendt 2016, 13).

This does not mean, however, that privacy and anonymity do not share any common features. They clearly overlap in their functions of shielding the democratic subject from interference by others, be they state actors, economic actors, or peers. However, while privacy withdraws both identity and content from public scrutiny, anonymity only shields identity while communicating content in the public sphere. Anonymity thus conveys one crucial feature of privacy, the concealment of identity, into the public sphere. It erodes the boundaries between the opposing binary of private versus public and facilitates a private form of engagement in the public discursive arena. By negating some aspects of the legally identified and physically embodied persona, anonymity transcends publicity and privacy, transforming private sentiments into political claims and transmitting them into the public sphere thus facilitating absence as presence.

The three sets of contradictory freedoms afforded by anonymity can be a useful tool for future research; one should keep in mind, however, that reality is not necessarily as simple as heuristics. One form of anonymous political participation does not simply result in one of these freedoms but rather entails a combination or even all of these tendencies to a certain degree. Anonymity's 
effects are always both positive and negative and remain contradictory. To further develop these categories, I suggest viewing them not as mutually exclusive, forming two poles on a continuum. Rather, their relations are to be understood as dialectical. Inclusion is defined by exclusion and vice versa. In other words, inclusion always rests on the exclusion of others, even if it is the exclusion of the one percent. Subversion by some aims at obtaining the submission of others. And what is an act of self-revelation by some is perceived as deception by others.

To illustrate this dialectic dynamic, I introduce a last example. In her book, Veil, Rafia Zakaria (2017) contends that in the context of the enforcement of burka bans and Islamophobic media discourses, the practice of publicly wearing the veil becomes an act of political participation. While the gendered practice of veiling women does fulfill the function of submission in a social context dominated by patriarchal norms, the veil becomes a tool for subversion confronting Islamophobia and claiming diversity in the public sphere. "Veils thus are a form of resistance and rebellion, an extension of the private space of the harem where [the women] are protected, into the public realm" (71f). Thus, in a dialectical move, patriarchal practices of submission are transformed into acts of subversion to counter state forces of submission. This dialectical move can also be investigated along the binary of honesty and deception. The German democratic theorist Hubertus Buchstein (1997) argues in his essay on online deliberation: "[T]he network presents an unreal world 
which allows all of us to create one or even more virtual identities... In most cases people pretend to have those positive characteristics they feel they lack. 'Virtual identities' overall tend to be somehow 'better' than the real ones" (258f, emphasis added). The literature on masked collective action offers a different explanation. It interprets identity creation as revealing aspects of the multifaceted self: "The mask is related to transition, metamorphoses, the violation of natural boundaries, to mockery and familiar nicknames. It contains the playful element of life" (Bakhtin 1996 [1968], 40). While this essay compared cases of deception with cases of honesty, in practice all cases contain both aspects as the boundaries between reality and fiction blur. Referring to the Guy Fawkes mask (V-mask) employed by Anonymous, Cambre (2014) states: "The generative trait of the V-mask, as Deleuzian multiplicity, like the quality of undecideability, ensures resistance to representation because it provides a riddle rather than a clear relationship, it is a non-identity acting as-if an identity, but instead of choosing one or the other it oscillates between them. It rejects dominant 'either/or' alternatives" (318). The dialectic of anonymity's contradictory freedoms is further complicated by a normative dimension. While the division in dichotomies of freedoms conducive and harmful to democracy might be a helpful heuristic, it is also necessary to think about positive and negative effects within each freedom. Suzanne Dovi (2009), for example, convincingly argues that exclusion is a necessary mode in democracy, as the access of privileged groups needs to be restricted in public decision-making bodies. Submission to commonly 
established rules and deception as expression of the multifaceted democratic subject are all positive aspects that contribute to a healthy democratic community, while inclusion can further privilege the more powerful, subversion can compromise security, and honesty might lead to hurt.

Lastly, future empirical research will need to take the particular contexts in which these three sets of contradictory freedoms occur into account. Identity performances afforded by anonymity are highly context-dependent, as they rely on three contextual axes: (1) the materiality of the communicative infrastructure, (2) the positionality of the communicative subject within established power structures, and (3) the configuration of identity knowledge. First, anonymous political participation depends on the materiality of the communicative infrastructure as it employs physical objects such as pens and paper, felt pens and bathroom walls, keyboards and computer screens, typewriters, masks, and digital objects such as avatars, emoticons, and pseudonyms. These objects play an essential role in anonymous identity performances. The perceived reality of the identity, for example, differs depending on whether physical masks or digital pseudonyms are used. The socio-cultural identity of the speaker is constructed differently if a political message is written on a bathroom wall or in a newspaper as a letter to the editor. The crucial role of communicative infrastructures becomes even more evident in the information age. The comparison of bathroom graffiti with posting in online forums illustrates this qualitative shift, which does not only 
affect the in/visibility of physically embodied identity but the dimensions of time and space. The increasing mediation of everyday communication establishes aspects of identity negation and creation as the norm. Anonymity becomes an integral part of our lives.

Second, the freedoms afforded by anonymity are affected by the positionality of the anonymous communicator within pre-existing social hierarchies. The social location affords different power resources to protestors and riot police, affluent and poor party funders, and heterosexual and homosexual graffiti scribblers. Linda Alcoff (1992) claims that the social position of the speaker alters the uttered content. Perceptions vary in accordance with the speaker's social status. These pre-established hierarchies along the lines of identity categories like race, class, and gender, can be disrupted or amplified by anonymity. Alison Kinney (2016) elaborates how the material object of the hood reverses its meaning when it is employed by activists to protest racism in comparison to its use in executions. While the anonymity afforded by the hood enhances the position of protestors, it dehumanizes and degrades the condemned criminal. Similarly, the veil can amplify patriarchal structures submitting its wearer, while also empowering its wearer to confront state repression (Zakaria 2017).

Third, configuration of identity knowledge form another crucial contextual condition of anonymous political participation. First, it matters which identity knowledge is conveyed by the identifiers used (pseudonyms, social security 
numbers, initials etc.) and which identity markers (gender, age, ethnicity etc.) of the legally identified and physically embodied persona are revealed.

Second, it matters who is anonymous within a communicative space and who is not. The struggle of masked riot police and masked protestors exemplifies this on an apparent level. A more subtle level can be illustrated by the question of whether online user identities are known to operators of websites and accessible to hackers and government agents. Third, it matters whether anonymous participants have previous knowledge of each other and have preestablished social relations or not. In workplace participation via anonymous online feedback tools, for example, participants might be formally unidentified but as the anonymity set is small, their identities might be easily deduced via social cues such as recognizable wording or content. In summary, the workings of anonymity's contradictory freedoms are affected by who knows what about whom within a communicative setting.

This article presents the first undertaking to root anonymity in democratic theory. It contributes to future research on anonymity in political participation by generating three sets of contradictory freedoms (a) inclusion and exclusion, (b) subversion and submission, and (c) honesty and deception. These freedoms are to be analyzed in the context of (1) the materiality of communicative infrastructure, (2) the social positionality of communicative subjects, and (3) the configuration of identity knowledge. Future research on anonymity will need to investigate the value and validity of these concepts in the pressing 
challenge of explaining the ambiguous workings of anonymity in political participation. These challenges appear ever more important as anonymity becomes a central feature of the information age.

\section{REFERENCES}

Akdeniz, Yaman. 2002. “Anonymity, Democracy, and Cyberspace.” Social Research 69: 223-37.

Alcoff, Linda. 1991. "The Problem of Speaking for Others." Cultural Critique 20(20): 5-32.

Asenbaum, Hans. 2017. "Cyborg Activism: Exploring the Reconfigurations of Democratic Subjectivity in Anonymous." New Media \& Society, online first, $1-21$.

Bakhtin, Mikhail. 1996. Rabelais and His World. Bloomington: Indiana University Press.

Barendt, Eric. 2016. Anonymous Speech: Literature, Law and Politics. Oxford: Hart Publishing.

Bartlett, Jamie. 2015. The Dark Net. London: Windmill Books.

Baxter, Hillary. 2015. "Masquerade, Pride, Drag, Love and Marriage.” In Masquerade: Essays on Tradition and Innovation Worldwide, ed. Deborah Bell. Jefferson: McFarland \& Company, 103-12. 
Berlin, Isaiah. 1969. "Two Concepts of Liberty." In Four Essays on Liberty, Oxford: Oxford University Press, 118-72.

Beyer, Jessica. 2014. "The Emergence of a Freedom of Information Movement: Anonymous, WikiLeaks, the Pirate Party, and Iceland." Journal of Computer-Mediated Communication (19): 141-54.

Blau, Adrian. 2004. “Against Positive and Negative Freedom.” Political Theory 32(4): 547-53.

Blee, Kathleen, and Amy McDowell. 2013. "The Duality of Spectacle and Secrecy: A Case Study of Fraternalism in the 1920s US Ku Klux Klan.” 36(2): 249-65.

Bruce, Caitlin. 2015. “The Balaclava as Affect Generator: Free Pussy Riot Protests and Transnational Iconicity." Communication and Critical/Cultural Studies 12(1): 42-62.

Bruner, Lane. 2005. "Carnivalesque Protest and the Humorless State.” Text and Performance Quarterly 25(5): 136-55.

Buchstein, Hubertus. 1997. "Bytes That Bite: The Internet and Deliberative Democracy." Constellations 4(2): 248-63.

Butler, Ella. 2006. "The Anthropology of Anonymity: Toilet Graffiti at the University of Melbourne.” University of Melbourne.

Cambre, Maria-Carolina. 2014. "Becoming Anonymous: A Politics of Masking.” In Educational, Psychological, and Behavioral 
Considerations in Niche Online Communities, eds. Vivek Venkatesh, Jason Wallin, Juan Carlos Castro, and Jason Edward Lewis. Hershey: Information Science Reference, 297-321.

Cardell, Kylie, and Emma Maguire. 2015. "Hoax Politics: Blogging, Betrayal, and the Intimate Public of A Gay Girl in Damascus.” Biography 38(2): 205-21.

Cohen, Jean. 1992. "Redescribing Privacy: Identity, Difference, and the Abortion Controversy." Columbia Journal of Gender and Law 3(3): 43117.

Coleman, Gabriella. 2014. Hacker, Hoaxer, Whistleblower, Spy: The Many Faces of Anonymous. London: Verso.

Craig, Scott. 1998. “To Reveal or Not to Reveal: A Theoretical Model of Anonymous Communication." Communication Theory 8(4): 381-407. da Vinci, Leonardo. 2005. The Da Vinci Notebooks. London: Profile Books. Diaz, Claudia, Stefaan Seys, Joris Claessens, and Bart Preneel. 2003.

“Towards Measuring Anonymity.” In Privacy Enhancing Technologies, eds. Roger Dingledine and Paul Syverson. Berlin: Springer, 54-68.

Dovi, Suzanne. 2009. "In Praise of Exclusion." The Journal of Politics 71(3): 1172-86.

Ferry, Anne. 2002. ““Anonymity': The Literary History of a Word.” New Literary History 33(2): 193-214. 
Freire, Paulo. 2005. Pedagogy of the Oppressed. 30th Anniv. New York: The Continuum International Publishing Group.

Fromm, Erich. 1941. Escape from Freedom. New York: Farrar \& Rinehart.

Gardner, James. 2011. “Anonymity and Democratic Citizenship.” William \& Mary Bill of Rights Journal 19(927).

Goffman, Erving. 1956. The Presentation of Self in Everyday Life. New York: Doubleday.

Griffin, Robert. 2017. “Anonymity and Authorship.” New Literary History 30(4): 877-95.

Groeneveld, Elizabeth. 2015. “Are We All Pussy Riot? On Narratives of Feminist Return and the Limits of Transnational Solidarity." Feminist Theory 0(0): 1-19.

Halpin, Harry. 2012. "The Philosophy of Anonymous: Ontological Politics without Identity." Radical Philosophy (176): 19-28.

Hunter, Christopher. 2002. "Political Privacy and Online-Politics: How ECampaigning Threatens Voter Privacy." First Monday 7(2).

Jonker, Hugo, and Wolter Pieters. 2010. “Anonymity in Voting Revisited.” In Towards Trustworthy Elections: New Directions in Electronic Voting, ed. David et al. Chaum. Berlin: IAVOSS/Springer-Verlag, 216-30.

Kinney, Alison. 2016. Hood. New York: Bloomsbury. 
Kopley, Emily. 2016. “Anon Is Not Dead: Towards a History of Anonymous Authorship in Early-Twentieth-Century Britain.” Studies in Book Culture 7(2): 1-23.

Kuran, Timur. 1993. "Mitigating the Tyranny of Public Opinion: Anonymous Discourse and the Ethic of Sincerity." Constitutional Political Economy 4(1): 41-78.

Leitner, John. 2015. “Anonymity, Privacy, and Expressive Equality: Name Verification and Korean Constitutional Rights in Cyberspace.” Journal of Korean Law 14(June): 167-212.

Lynch, Michael, and Anthony Madonna. 2013. "Viva Voce: Implications from the Disappearing Voice Vote, 1865-1996.” Social Science Quarterly 94(2): 530-50.

MacCallum, Gerald. 1967. "Negative and Positive Freedom.” Philosophical Review 76(3): 312-34.

Marx, Gary. 1999. "What's in a Name? Some Reflections on the Sociology of Anonymity." The Information Society 15(2): 99-112.

McCarthy, Matthew. 2015. "Toward a Free Information Movement." Sociological Forum 30(2): 439-58.

McDonald, Kevin. 2015. "From Indymedia to Anonymous: Rethinking Action and Identity in Digital Cultures." Information, Communication \& Society 18(8): 968-82. 
Mill, John Stuart. 1946. On Liberty and Considerations on Representative Government. Oxford: Blackwell.

Moore, Alfred. 2017. “Anonymity, Pseudonymity, and Deliberation: Why Not Everything Should Be Connected." The Journal of Political Philosophy $0(0): 1-24$.

Morris, Adam. 2012. "Whoever, Whatever: On Anonymity as Resistance to Empire." Parallax 18(4): 106-20.

Nguyen, Mimi Thi. 2015. “The Hoodie as Sign, Screen, Expectation, and Force.” Signs 40(4): 791-816.

Nissenbaum, Helen. 1997. "Toward an Approach to Privacy in Public: Challenges of Information Technology." Ethics \& Behavior 7(3): 20719.

Nissenbaum, Helen. 1999. "The Meaning of Anonymity in an Information Age." The Information Society: An International Journal 15(2): 141-44.

Nissenbaum, Helen. 2010. Privacy in Context: Technology, Policy, and the Integrity of Social Life. Stanford: Stanford University Press.

Pfitzmann, Andreas, and Marit Hansen. 2010. A Terminology for Talking about Privacy by Data Minimization: Anonymity, Unlinkability, Undetectability, Unobservability, Pseudonymity, and Identity Management. 
http://www.maroki.de/pub/dphistory/2010_Anon_Terminology_v0.34.pd f.

Reiman, Jeffrey. 1976. "Privacy, Intimacy, and Personhood." Philosophy \& Public Affairs 6(1): 26-44.

Rodriguez, Armado, and Robin Clair. 1999. "Graffiti as Communication: Exploring the Discursive Tensions of Anonymous Texts." The Southern Communication Journal 65(1): 1-15.

Ruiz, Pollyanna. 2013. "Revealing Power: Masked Protest and the Blank Figure." Cultural Politics 9(3): 263-79.

Schmitz, Rachel. 2016. "Intersections of Hate: Exploring the Transecting Dimensions of Race, Religion, Gender, and Family in Ku Klux Klan Web Sites.” Sociological Focus 49(3): 200-214.

Smith Ekstrand, Victoria, and Cassandra Imfeld Jeyaram. 2011. “Our Founding Anonymity: Anonymous Speech During the Constitutional Debate." American Journalism 28(3): 35-60.

Spiegel, Jennifer. 2015. "Masked Protest in the Age of Austerity: State Violence, Anonymous Bodies, and Resistance 'In the Red."' Critical Inquiry 41(4): 786-810.

Steinholt, Yngvar. 2013. “Kitten Heresy: Lost Contexts of Pussy Riot’s Punk Prayer." Popular Music and Society 36(1): 120-24. 
Suler, John. 2004. “The Online Disinhibition Effect." CyberPsychology \& Behavior 7(3): 321-26.

Tiqqun. 2008. How Is It to Be Done?

http://cnqzu.com/library/Politics/Invisible-Committee-How-it-bedone.pdf.

Wallace, Kathleen. 1999. “Anonymity.” Ethics and Information Technology 1(1): 23-35.

Wagner Decew, Judith. 2015. "The Feminist Critique of Privacy: Past Arguments and New Social Understandings." In Social Dimensions of Privacy, eds. Beaate Roessler and Dorota Mokrosinska. Cambridge: Cambridge University Press, 85-103.

Warren, Samuel, and Louis Brandeis. 2016. "The Right to Privacy.” Harvard Law Review 4(5): 193-220.

Wesch, Michael. 2012. “Anonymous, Anonymity, and the End(s) of Identity and Groups Online: Lessons from the 'First Internet-Based Superconsciousness."” In Human No More: Digital Subjectivities, Unhuman Subjects, and the End of Anthropology, eds. Neal Whitehead and Michael Wesch. Colorado: University Press of Colorado, 89-104.

Westin, Alan. 1984. "The Origins of Modern Claims to Privacy.” In Philosophical Dimensions of Privacy: An Anthology, ed. Ferdinand Schoeman. Cambridge: Cambridge University Press, 56-74. 
Wilde, Oscar. 2007. The Critic as Artist (Upon the Importance of Doing Nothing and Discussing Everything). Stockport: Mondial.

Woo, Jisuk. 2006. "The Right Not to Be Identified: Privacy and Anonymity in the Interactive Media Environment." New Media \& Society 8(6): 949-67.

Zakaria, Rafia. 2017. Veil. New York: Bloomsbury. 